\title{
Research-design model for professional development of teachers: Designing lessons with physics education research
}

\author{
Bat-Sheva Eylon and Esther Bagno \\ The Science Teaching Department, Weizmann Institute of Science, Rehovot, Israel, 76100
}

(Received 10 January 2006; published 21 September 2006)

\begin{abstract}
How can one increase the awareness of teachers to the existence and importance of knowledge gained through physics education research (PER) and provide them with capabilities to use it? How can one enrich teachers' physics knowledge and the related pedagogical content knowledge of topics singled out by PER? In this paper we describe a professional development model that attempts to respond to these needs. We report on a study of the model's implementation in a program for 22 high-school experienced physics teachers. In this program teachers (in teams of 5-6) developed during a year and a half (about $330 \mathrm{~h}$ ), several lessons (minimodules) dealing with a topic identified as problematic by PER. The teachers employed a systematic researchbased approach and used PER findings. The program consisted of three stages, each culminating with a miniconference: 1. Defining teaching and/or learning goals based on content analysis and diagnosis of students' prior knowledge. 2. Designing the lessons using PER-based instructional strategies. 3. Performing a small-scale research study that accompanies the development process and publishing the results. We describe a case study of one of the groups and bring evidence that demonstrates how the workshop advanced: (a) Teachers' awareness of deficiencies in their own knowledge of physics and pedagogy, and their perceptions about their students' knowledge; (b) teachers' knowledge of physics and physics pedagogy; (c) a systematic research-based approach to the design of lessons; (d) the formation of a community of practice; and (e) acquaintance with central findings of PER. There was a clear effect on teachers' practice in the context of the study as indicated by the materials brought to the workshop. The teachers also reported that they continued to use the insights gained, mainly in the topics that were investigated by themselves and by their peers.
\end{abstract}

DOI: 10.1103/PhysRevSTPER.2.020106

PACS number(s): 01.40.jh, 01.40.gb, 01.40.ek, 01.40.E-

\section{INTRODUCTION}

In the past decade physics education research has accumulated a significant body of knowledge relevant to teachers' practice. ${ }^{1}$ The Resource Letter-PER (physics education research), ${ }^{1}$ published in the American Journal of Physics, offers an exhaustive bibliography of research papers categorized according to empirical studies, theoretical perspectives, and research-based instructional materials. McDermott and Redish, the authors of this paper, write in their abstract: "The purpose of this Resource Letter is to provide an overview of research on the learning and teaching of physics. The references have been selected to meet the needs of two groups of physicists engaged in physics education. The first is the growing number whose field of scholarly inquiry is (or might become) physics education research. The second is the much larger community of physics instructors whose primary interest is in using the results from research as a guide for improving instruction." While research in physics education has influenced the practice of some college physics instructors, ${ }^{2}$ there are still many practitioners both at the college level but mostly at the high-school level who are not aware of the PER endeavor and do not consume its results into their practice. As pointed out by Smith and Neale, ${ }^{3}$ even if teachers are aware of the PER results, the increased knowledge of students' understanding does not ensure that they can respond in appropriate ways when students exhibit misconceptions.

How can one increase the awareness of teachers to the existence of a vast body of knowledge gained through physics education research? How can one bring them to change their views regarding the importance of PER results? How can one provide teachers with capabilities to use PER-based innovative instructional strategies and integrate them into their existing practice? In this paper we describe a model that attempts to respond to these needs and a study of its implementation with high-school physics teachers. In addition to the central goal of professional development in the area of using PER, the model aims at other central goals singled out as important in teachers' expertise and accomplishment. ${ }^{4,5}$ These goals include teachers' content knowledge, pedagogical content knowledge, systematic design of lessons, and collaboration with peers (belonging to a "community of practice"). We will show below how the model advances the goal of using PER simultaneously with all the other goals.

Research on teachers' professional development shows that bringing about profound changes in teachers' views and practices requires a long-term comprehensive program. ${ }^{6-8}$ Many of the successful professional development programs engage teachers in inquiries based on real classroom contexts. ${ }^{9}$ Since in this paper we are concerned with the use of PER results, we suggest that aspects of PER would become an integral part of the inquiries carried out by teachers and that they will experience the consumption of its results in their classrooms. Accordingly, in the program described in this paper, teachers develop over a long period of time several lessons (minimodules) dealing with a topic identified as problematic by PER. The teachers employ a systematic research-based approach of development and use the PER findings. They start from the diagnosis of students' prior knowledge, design lessons aimed at predefined learning goals, use PER-based instructional strategies, and carry out 
"assessment for learning". ${ }^{10}$ The approach involves successive refinements of the lessons-a design study methodology. ${ }^{11}$

We described above the importance of promoting the goal of using PER. In the following paragraphs we elaborate briefly on each of the central goals of the program

Goal 1: Awareness. Teachers' awareness of the need to learn is a prerequisite for any professional development. ${ }^{12}$ Loucks-Horsley et al. ${ }^{13}$ in their chapter about strategies for professional learning, select the strategies according to the purposes they have to fulfill. Increasing awareness and eliciting thoughtful questioning on the part of the teachers is the first goal on their list. In the European research and development project, "Science Teacher Training in an Information Society," ${ }^{14}$ each set of workshop activities was built as a coherent sequence, starting from developing an awareness of the issues the teachers had to deal with. The need to address this goal was crucial in the program described in this paper. This program was planned to be carried out with experienced physics teachers possessing a strong background in the discipline. These teachers would agree that they lack expertise in a contemporary topic such as astrophysics, but would not admit a lack of knowledge in the basic topics taught in school (e.g., what is the mechanism driving the current in an electric circuit). Similarly, they would admit a lack of expertise in some new laboratory techniques such as using sensors, or using a spreadsheet to build models of physics phenomena, but would not identify the need to participate in programs aimed at upgrading their pedagogical content knowledge (see below). Therefore, the first and most important goal of the program was to raise teachers' awareness of deficiencies in certain aspects of their knowledge and practice and how PER can contribute to these aspects.

Goal 2: Knowledge (content knowledge and pedagogical content knowledge). A report of the $\operatorname{NCTAF}^{15}$ mentions two critical findings regarding teachers' content and pedagogical content knowledge: First, the teacher's expertise is one of the most important factors in student learning "Teachers who know a lot about teaching and learning and who work in environments that allow them to know students well, are the critical elements of successful learning." 16 Second, teachers' knowledge of the subject matter, student learning and development, as well as teaching methods are all important elements of teacher effectiveness.

Content knowledge. Teachers must have a rich and flexible knowledge of content in order to foster students' conceptual understanding. ${ }^{17}$ In addition, teachers must understand the processes used to establish new knowledge and determine the validity of claims. ${ }^{18-21}$ Hollon, Roth, and Anderson, ${ }^{22}$ show, however, that good mastery of the disciplinary knowledge does not guarantee that teachers can effectively use this knowledge in their teaching. Thus, pedagogical content knowledge is an essential component of teachers' expertise as described below.

Pedagogical content knowledge (PCK). First introduced by Shulman, ${ }^{4,23}$ this type of teachers' knowledge is distinguished from general pedagogical knowledge by being intertwined with content knowledge. There are varied conceptualizations of PCK in the literature. ${ }^{24}$ For the purpose of this paper we adapted the description of Magnusson, Krajcik, and
Borko, ${ }^{25}$ who identified five important elements of PCK: teachers' orientations towards teaching science (knowledge and beliefs about the goals and processes of teaching science at a particular grade level), teachers' knowledge of science curricula, teachers' knowledge of students' understanding of science, teachers' knowledge of instructional strategies, and teachers' knowledge of assessment of scientific literacy (what and how to assess).

Goal 3: Systematic research-based design of lessons. This is a fundamental pedagogical skill that each teacher must possess. Here we emphasize the integration of this skill with content knowledge and pedagogical content knowledge in order to transform and represent knowledge in forms suitable for particular students' learning..$^{25,26}$ The use of PER methodologies and results are important in achieving this goal. The development of this skill, essential for every practicing teacher, is evident in the Japanese "lesson study" approach, where teachers work collaboratively in planning, teaching, observing, and reflecting on lessons they develop. Stigler and Hiebert, ${ }^{27}$ recommended to test this approach in the US, and there is a growing interest in its use in teacher development programs. $^{28}$

Goal 4: A community of practice. Since many high-school physics teachers in Israel and in other countries are the only physics teachers in their school, they do not have opportunities to collaborate with colleagues. Borko, ${ }^{17}$ in her AERA presidential address, pointed out that strong professional communities of teachers can foster teacher learning. Little, ${ }^{29}$ provides evidence relating instructional improvement to communities of practice. Although there is no direct linkage between teachers' interactions and their students' achievement, researchers report some anecdotal evidence that teacher communities have an effect on students. ${ }^{30}$ Collaboration between teachers is only the first step towards forming a "community of practice". Communities involve also "development of group identity and norms for interaction, communal responsibility for the regulation of norms and behavior and willingness of community members to assume responsibility for colleagues' growth and development". ${ }^{30}$

In the following sections we elaborate on the structure of the model. We then describe an in-service program for physics teachers that implemented the model, and an empirical study that accompanied its implementation. The impact of the program was examined during the implementation as well as several years later.

\section{THE MODEL}

\section{A. Rationale}

Physics educators, responsible for preservice training, have developed several models to raise the awareness of prospective teachers to PER and its use in teaching. For example, one of the approaches involves teachers reproducing segments of existing research. ${ }^{31}$ Another way of bringing the results of research to teachers is through PER-based curricula or frameworks, e.g., "Modeling Workshops," 32 or the "Tutorials." ${ }^{33}$ As mentioned above, in this study the core of the professional development program involved the design of lessons. This strategy is recommended in the literature,${ }^{13}$ and 
is thought to promote mainly the practice of teaching as well as the building of knowledge (p.46). Additional strategies recommended by Loucks-Horsley et al. ${ }^{13}$ involve action research, examining student work and study groups. These strategies are important in advancing additional desired goals such as developing awareness and reflection on practice. In her summary of effective professional development programs, Roth, ${ }^{9}$ lists the following features: "…engaging teachers actively in collaborative long-term problem-based inquiries, treating content learning as central and intertwined with pedagogical issues, and allowing teachers to investigate teaching and learning issues in real classroom contexts focused on specific curriculum used in their own classrooms." The approaches mentioned above can be described as having the four characteristics described by the National Research Council (NRC) study, ${ }^{34}$ concerning teachers' learning: learner-centered; knowledge-centered; assessment-centered; and community-centered.

The model that we designed blends these strategies and attempts to respond to teachers' needs. Our rationale for asking teachers to develop the minimodules was based on the assumption that teachers would find it natural to design a lesson, since this is what they do all the time. Moreover, this kind of activity is a natural arena for them to manifest their knowledge in physics teaching, giving them the respect that is so essential for professional development. The other components of the model, e.g., collaboration and the systematic research-based approach, are less natural to teachers and require special training. We hoped that as a result of getting the teachers involved in the process of designing lessons, implementing them in their classes, and examining their students' work, they will change their views regarding the importance and use of PER. Moreover, we hoped that this process will bring about the professional development of teachers regarding their physics knowledge and their pedagogical content knowledge.

\section{B. Description of the model}

The model consists of the following ten consecutive steps organized into three stages. Each stage culminates with a miniconference. Each step is carried out through guided activities involving detailed instructions and guidance in how to carry out the step as well as feedback. The development of the minimodules is carried out in the context of the whole class and group work.

\section{Stage I: Defining teaching and/or learning goals based on content analysis and diagnosis of students' prior knowledge}

(1) initial definition of goals; (2) review of the literature; (3) diagnosis; (4) revision of goals; Conference I.

\section{Stage II: Designing the lessons}

(5) innovative learning strategies; (6) initial planning; (7) design of lessons; Conference II.

\section{Stage III: Performing a small-scale research study that accompanies the development process and publishing the results}

(8) design and implementation of the study; (9) summary of research; (10) a paper summarizing the process; Conference III.

Rationale. The first stage of the model attempts to get teachers to realize the need to introduce some innovation in the particular topic. Unlike the usual process of planning a teaching sequence, where the goals of the lessons are predefined by external authorities, such as the syllabus, stage I of the model, enables teachers to identify problems encountered by them (as learners) and by their students (through diagnosis) and can motivate them to design lessons customized to their own needs.

The summary in the first conference serves as a means for consolidating the knowledge gained by teachers during this stage and by focusing and redefining the goals for the lessons. The second stage is aimed at advancing the planning, starting with an acquaintance with new instructional strategies, the model leads teachers through a process of successive refinements of goals and means, an approach taken by expert curriculum developers. The process involves several means: expert consultation, critique by peers, and observation of the instructional strategies used by colleagues. This experience forms the basis for the design of the minimodules. The conference can provide an additional opportunity to examine the product and can lead to some adjustments. The third stage is based on the assumption that the activities carried out in the previous stages of the model would motivate the teachers to evaluate the instruction that they have developed, study their students' learning, and report on their results to participants and other colleagues.

\section{THE STUDY}

\section{A. Context and sample}

The model was implemented as a workshop within a three-year program aimed at the professional development of leading-teachers. The study was carried out in the context of this workshop. A group of about 50 senior high-school physics teachers signed up for the program, 22 of them were selected for this program on the basis of recommendations and an interview. The teachers met once a week for a full day $(8 \mathrm{~h})$ for three years. The development of the "minimodules" workshop lasted about a year and a half, for a total of $330 \mathrm{~h}$.

The teachers formed four groups of 5-6 teachers each that were interested in developing a certain topic. The members of each group switched responsibility in organizing the various assignments of the workshop topic and had one of the program leaders as a mentor. During the meetings, the activities were carried out in the whole class and in groups. Inbetween meetings the groups met to carry out assignments. During the meetings the mentors acted as facilitators and also helped in organizing the flow of work in and between the meetings.

\section{B. Goals and research question}

The study was concerned with the contribution of the workshop to the professional development of the participat- 
ing teachers in terms of the goals outlined above: awareness, knowledge (content, PCK and PK), systematic design of lessons, and community of practice. Accordingly, the following research question was studied: How did the model contribute to the attainment of the desired goals?

\section{Methods of investigation}

The study employed both qualitative and quantitative methods of analysis. Data were collected on all the groups participating in the workshop during its implementation and several years later. The data consist of the following elements:

(1) Documentation of the meetings: observations and transcriptions of audiotapes of all the whole class meetings and the discussions among the teachers during the group work as well as the materials developed by the teachers during the workshop (e.g., teachers' concept maps regarding the topic "from electrostatics to currents," diagnostic questionnaires, versions of the minimodules).

(2) Students' work brought by teachers to the workshop.

(3) Informal conversations with teachers.

(4) The journal of the course-leaders: it included plans of the meetings and remarks reflecting on the implementation.

(5) Questionnaires about teachers' views of the contribution of the course, immediately after the course and six years later.

Because of lack of space, in this paper we describe in detail a case study of six physics teachers who worked as a group on the topic "From electrostatics to currents" and substantiate the findings with data emerging from the other groups. We shall not report in detail the results of the questionnaires, but will mention the major findings.

\section{The topics of the minimodules}

The selection of appropriate topics to be offered to teachers is essential for the success of the model. There are several considerations in choosing the topics of the minimodules: relevance to the teachers' ongoing practice, topics identified as problematic in the educational research literature, topics requiring abstract reasoning that requires concretization, topics dealing with powerful ideas, etc. In the present study the teachers were offered, in the beginning of the workshop, the following four topics for choice: (1) The relationship between Newton's first and second laws. (2) Introduction to waves. ${ }^{35}$ (3) From electrostatics to currents. ${ }^{36}$ (4) Electromagnetic induction. ${ }^{37}$ Each teacher chose a topic, and four groups were formed accordingly.

\section{ANALYSIS AND RESULTS}

In this section we describe a case study of one of the groups; relevant results from the work of other groups; results from teachers' self-reports immediately after the completion of the course and several years later. We will show how the workshop advanced: (a) Teachers' awareness of deficiencies in their own knowledge of physics and peda-

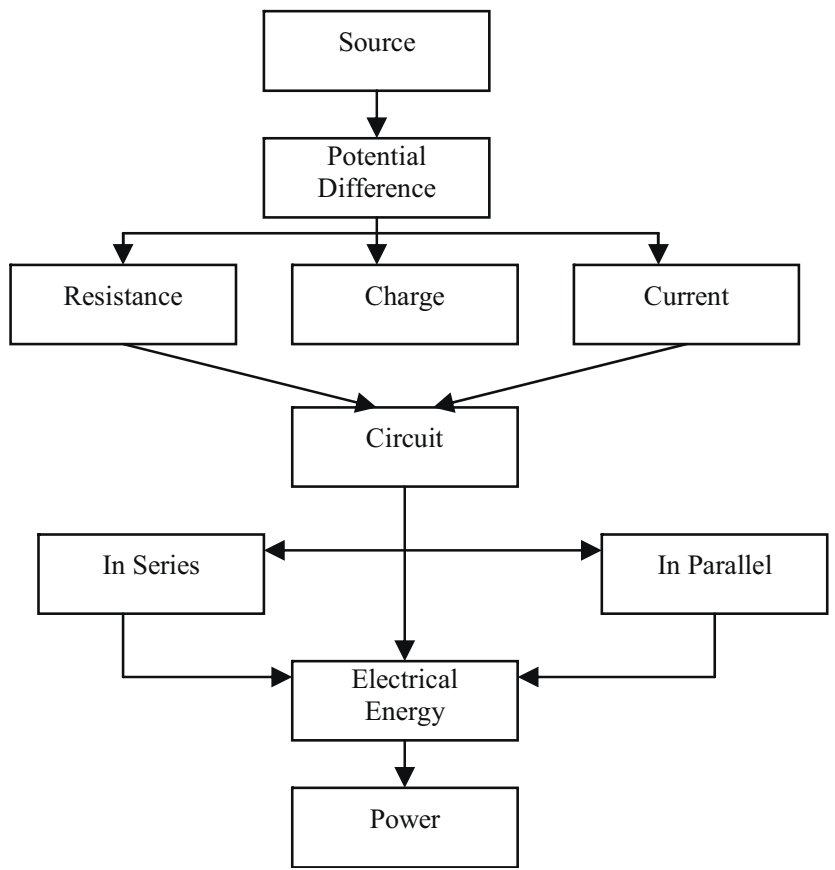

FIG. 1. The concept map drawn initially by the "From electrostatics to currents" group describing the central concepts involved in the transition from electrostatics to currents.

gogy, and their perceptions about their students' knowledge; (b) all aspects of teachers' knowledge; (c) a systematic research-based approach to the design of lessons; (d) the formation of a community of practice; and (e) acquaintance with central findings of PER. The section concludes with a summary of the evidence supporting the above claims for each of the goals.

\section{A. A case study of six teachers}

\section{Stage I: Defining teaching and/or learning goals based on content analysis and diagnosis of students' prior knowledge}

Step 1: Initial definition of goals. Teachers construct a concept map describing the concepts and principles involved in their planned minimodule. They construct the maps initially as individuals, and then compare and discuss the maps with their peers, attempting to reach a consensus, and ultimately coming up with one or more group maps. In general, this was the mode teachers worked together along the whole workshop. They attempted to identify commonalities but respected different views.

Results. Figure 1 shows the concept map drawn by the "From electrostatics to currents" group. The teachers did not initially see the significance of this task and the importance of the topic. In other words, the "teachers did not know that they do not know." The process of creating and discussing a concept map turned out to be very illuminating to all the groups in terms of their physics knowledge as well as the pedagogy of teaching the topic.

As can be seen, there is almost no linkage between electrostatics and currents: The concept of the electric field is 
TABLE I. Teachers' present their review of the literature.

\section{(a) Issues regarding the physics raised by the review}

1. How does the current "know" how to split in a junction?

2. If the electric field exerts force on the charges, why is the drift velocity constant?

3 . How do the charges know how to move in a meandering wire?

(b) Selected insights regarding the teaching and learning of physics from the review

1. How do students explain current flow in an open circuit and what can be done about it?

2. There is a gap between students' conceptions of electric fields in the contexts of electrostatics and electric circuits: electric field in electrostatics is usually conceived by students as a force that causes charges to move, whereas in circuits, the electric field is conceived as a theoretical concept derived from the concept of the potential difference. Introducing the changes in the distribution of surface charges in electric circuits can help in bridging the gap.

3. The analysis of dc circuits is usually based on energy considerations without referring to the microscopic aspects inside and outside the circuit.

\section{(c) Selected instructional strategies from the review}

1. Murzin, for example, describes Drude's model as an explanation of charge flow in a circuit and the relationship between $j$ and $E$.

2. Parker and Chabay \& Sherwood use the surface charge distribution to explain the electric field inside and outside a current-carrying conductor.

3. Jefimenko suggests interesting experiments demonstrating electric fields inside and outside meandering wires.

missing; the concept of charge is not related to the concept of current; and the directions of the arrows relating to the concepts do not reflect a coherent understanding. These results are consistent with previous research findings. ${ }^{36}$

An analysis of the teachers' discussions during this session confirmed that the causal relationship between the electric field and current was deficient. They were frustrated to find out that in spite of their experience, they still lacked basic knowledge of physics.

The following are excerpts from these discussions:

(i) Although the topic of currents seems to be very simple, the truth of the matter is that I have an uneasy feeling when I teach it.

(ii) Well, sometimes I smooth things over.

(iii) The whole issue of an electromotive force (EMF) source is like a black box for me. What does the battery do? I suspect that even chemistry teachers cannot provide an answer.

(iv) I suggest asking Zvi (an expert physics teacher) to come to the next meeting.

In the course-leader journal, written after this session, it was noted that the teachers had a hard time with the physics of this topic and they asked for extra time to learn more physics.

Step 2: Review of the literature. Teachers review the literature on physics as well as physics learning relevant to their topic, and report on the main learning difficulties and instructional strategies. The process is guided by the course leaders, but teachers are asked to expand the suggested list of references.

Results. The teachers were referred to the literature concerning the physics of surface charge distribution that causes the charges to flow, and to papers about innovative instruc- tional strategies in this topic. ${ }^{38}$ Table I presents the original list of the teachers' review of the literature as presented in conference I.

After discussing the review of the literature, one of the teachers said:

"You know what? The physics here is really complicated; it is nice to find out that people tackle the same problems everywhere."

Step 3: Diagnosis. Teachers design, administer, and analyze a diagnostic questionnaire consisting of a few "simple" questions to examine students' understanding.

Results. Teachers usually compose examinations quite easily. However, the requirement to compose a diagnostic tool aimed at well-predefined goals was a new experience for many of them. Besides the enrichment of their subject matter knowledge and their pedagogical content knowledge, this stage of the workshop enriched their general pedagogical knowledge as well. Teachers raised questions and dwelled on issues unfamiliar to them such as: "What is a diagnostic tool? Does it have to be a questionnaire? What do we want to find out about students' understanding? What do we mean by understanding?" According to the course-leader journal, following the development of the diagnostic tool, the teachers suggested changing the plan of the course and asked for additional lectures supplying information about the ideas of "diagnosis" and "understanding."

The group designed questions focusing on the relationship between the electric field and current at different points of a dc circuit at different times. Since the electric field between the plates of a capacitor is studied in electrostatics and the charging of a capacitor is studied in dc circuits, the teachers decided to focus the questionnaire on the charging of a capacitor. Table II presents the list of goals for the diagnostic questionnaire. 
TABLE II. Goals of the diagnostic questionnaire as listed by the teachers.

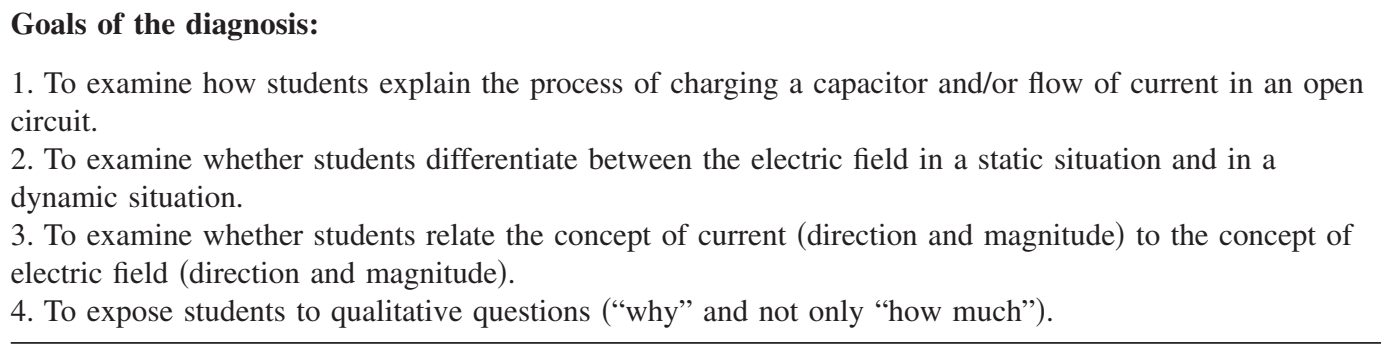

Since all the topics of the minimodules were based on the existing high-school physics syllabus, teachers were able to find quite easily the appropriate lesson for administering the diagnostic questionnaire. This choice of topics enabled them to incorporate research-based materials into their practice. The diagnostic questionnaire was administered to 93 highschool students studying A-level physics, after they had finished electrostatics, dc circuits, and the charging and discharging of a capacitor. We asked the teachers to collect their students' answers and to analyze the results cooperatively with their colleagues in the group and the mentor. Table III describes the diagnostic questionnaire, the analysis of the results, and representative statements of teachers regarding the data.

The following are comments made by the teachers during the analysis of the data:

(i) Generally speaking, most of the students explain dc phenomena through energy-based considerations and not through forces on charges.

(ii) They relate electric fields in dc circuits to potential differences and not to charges.

(iii) Students have difficulties with transients: electric fields between the plates of a capacitor and in the wires of the circuit.

(iv) I imagined that all my students would know that after charging there is an electric field between the plates of a capacitor, I'm disappointed.

(v) You know what? A few students even said that this questionnaire caused them for the first time to think about dc circuits in terms of an electric field.

Step 4: Redefinition of goals and conference I. Teachers change the initial goals on the basis of findings emerging from steps 2 and 3 . In the conference teachers summarize the first stage of the model. They share their ideas with colleagues, invited scientists, and science educators. They discuss their initial concept maps; the review of the literature; the diagnostic tool developed to identify students' difficulties; the results of administering the diagnostic tool in the classrooms; and some preliminary thoughts for the planned minimodule. The teachers summarize in a booklet all these outcomes including the input of the conference participants.

Results. Presenting ideas to an audience is not a new experience for teachers. Nevertheless, the requirement to present the outcomes of the first stage of the model to colleagues and distinguished guests was an intriguing and exciting event for most of the participating teachers. All teachers worked hard crystallizing and summarizing their own insights regarding the relevant subject matter and utilized the data gathered from their classes. The exposure to learning and teaching problems identified by their peers also increased their awareness of the various difficulties, legitimated free discussions, and increased teachers' motivation to learn more about physics and the teaching of physics. The following are excerpts of statements from an interesting discussion held among the teachers and the guests about the physics of the topic and the recommended ways to teach it.

(i) Is there a nonconservative electric field in the battery?

(ii) It is really difficult to explain what is going on in an open circuit.

(iii) It is easy to explain currents through potential and energy-based considerations, but how is it done with forces?

(iv) It is written in the literature that the electric field is not produced by the moving charges. There are static charges on the conductor that make the current flow. Now here is my question: Do these static charges produce an electric field outside the conductor and no electric field inside?

As a result of the conference, the group was able to define more precisely the scope and the goals of the minimodule. As one of the teachers put it: "We should focus on strengthening the continuity between electrostatics and currents. We should also show that both the electrostatics and the electrodynamics phenomena originate from Coulomb's law and the appropriate surface charge distribution."

The main goal of the minimodule, as summarized in the booklet prepared for conference I was: To apply the principles of electrostatics-forces, fields, and electric potential, to de circuits.

Figure 2, presented in the conference, explicitly represents this new conception of goals.

The following is the list of new goals as stated by the teachers: The physics of the minimodule will focus mainly on the "missing link"-between the two dashed lines in the concept map.

(a) Distribution of charges: Reasons for the distribution; shapes of the distribution.

(b) Direction of the electric field inside and outside the conductor.

(c) Magnitude of the electric field and its dependence on the parameters of the conductor: lengths, area, and type of the material.

(d) Influence of local factors vs the emf of the source on the electric field in certain points of the conductor.

(e) The current in an open circuit, the capacitor. 
TABLE III. The diagnostic questionnaire designed by the teachers, their analysis of data collected from 93 high-school students, and statements from their presentation of the results in conference I.

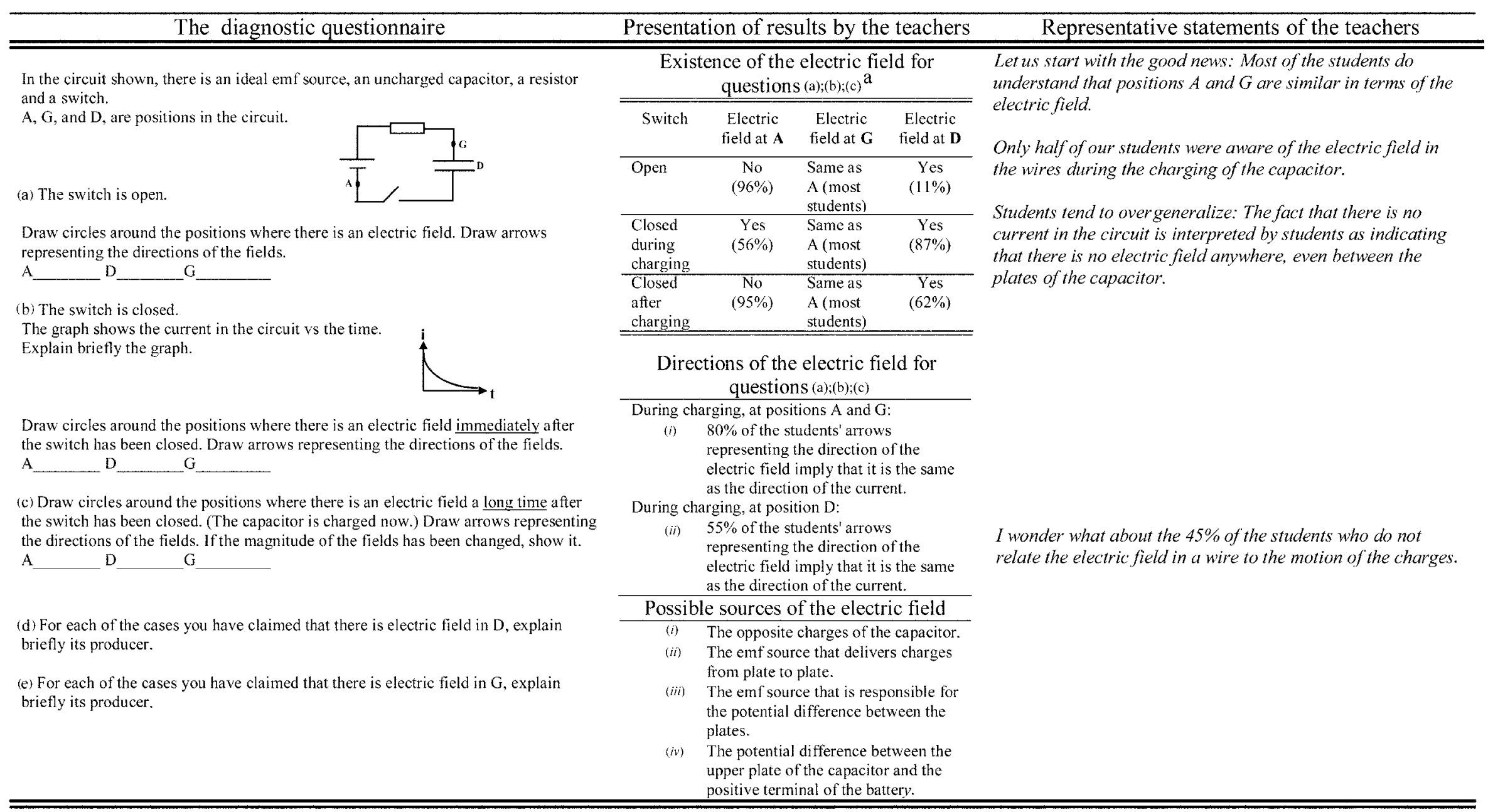

a The entries in the first subtable of the second column list the correct answers and the percentages of students providing them. 


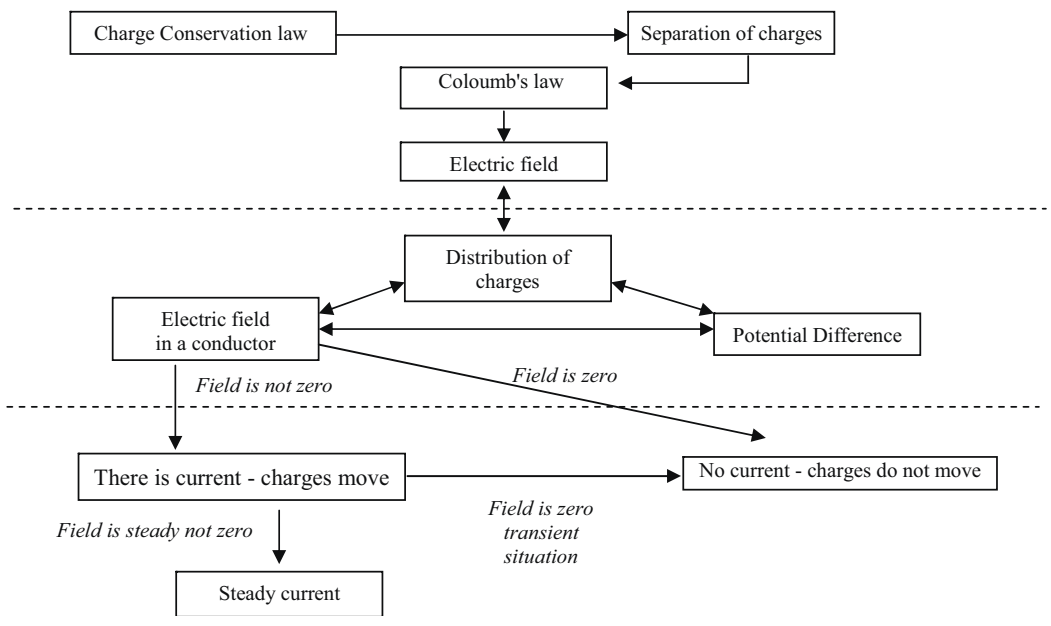

FIG. 2. The concept map and list of new goals, presented by the "From electrostatics to currents" group in conference I. This concept map has three main components (separated by the two dashed lines): some concepts of electrostatics, some concepts of electric circuits, and an interface relating the two, defined by the teachers as the new target of their minimodule.
As can be seen, this is a much more focused set of goals than the initial goals presented in the initial concept map (see Fig. 1).

\section{Stage II: Designing the lessons}

Steps 5 and 6: Innovative learning strategies and initial planning. In step 5, each group is requested to read about a research-based instructional strategy, ${ }^{39}$ present it to the whole class, and lead a discussion relating to the challenges and the advantages of the strategy. In addition, teachers learn about the initiatives of fellow expert teachers. A special day is dedicated to step 6 in which teachers present their initial ideas using some of the strategies in step 5 and consult expert physics teachers, physics educators, and physicists. This activity leads to a preliminary plan for the minimodule entitled "The Story of the minimodule." The plan consists of a short description of the goals and the rationale for the means of achieving them using the innovative instructional strategies. The story of each minimodule is presented to the whole class and critiqued by peers.

Results. At this point after the systematic and researchbased plan that narrowed down the set of goals, the teachers were eager to design lessons "solving" the problems identified through the previous steps of the workshop. They requested to extend the time allocated for the development of the minimodules. We reminded the teachers to screen again the materials offered previously in the "Literature review" step. ${ }^{38}$ The "From electrostatics to currents" group dealt with Chabay and Sherwood's textbook, which they found to be very useful.

Four expert physics teachers from the Science Teaching Department offered consultation to the groups regarding the design of the lessons. In order to scaffold the design process, we gave the teachers a structured form to guide the "The Story of the minimodule" - an abstract describing the future plan of the lessons. The plan was critiqued by peers (see Table IV).

During this session, the following remarks were made by the teachers:

(i) Usually we decide what to teach and we just teach it. This planning game is really interesting and it is not a waste of time. (ii) Well, this planning activity clarifies what is really important when you design a lesson.

(iii) I'm so glad to have the opportunity to meet all these expert physics teachers and to learn from them. Zvi's movie about the electric field in the vicinity of a currentcarrying conductor is a wonderful teaching tool.

Step 7: Design of lessons and conference II. Teachers design a version of the materials based on the information compiled regarding students' difficulties as well as techniques developed by the teachers to overcome these difficulties. In conference II teachers present and discuss the rationale of the lessons and the relevant learning materials.

Results. Teachers were expected to design the lessons within the framework of the meetings and allocate some minimal time in their home. Although it was not required, all the groups communicated via emails, forums, and phone calls, and developed the lessons accompanied with all the relevant materials. Further contributions of the scientists, physics educators, and peer teachers in conference II refined the product and turned it into a comprehensive set of lessons used until now by all the teachers in the group. The minimodule developed by the group is a 21-page booklet that includes the following: an introduction, a rationale explaining how to teach dc circuits in relation to electrostatics and a detailed description of all the lessons accompanied with the materials.

\section{Stage III: Performing and publishing the results of a small- scale research study that accompanies the development process}

Steps 8 and 9: Design and implementation of a study; summary of research and conference III. In step 8 the teachers formulate research questions, design the structure of the study, design research tools, implement the minimodules in their classes, conduct the relevant research, and check the effectiveness of the innovative lessons on their students' learning. In step 9 the teachers analyze the results of the study and present them to their peers. Conference III is the highlight of the workshop. Teachers report their findings and reflect on the whole process.

Results. Since the topics of the minimodules were chosen according to the existing high-school physics syllabus, the 
TABLE IV. The "The Story of the minimodule"-an abstract describing the future plan of the lessons as presented by the "From electrostatics to currents" group.

The story of the minimodule "From electrostatics to currents"

Possible place in the teaching sequence: One out of three possibilities.

1. After teaching electrostatics as an introduction to dc circuits.

2. After the "traditional" teaching of dc circuits, as an introduction to capacitors.

3. After teaching electrostatics and dc circuits as a summary topic

Goals of the minimodule: To apply the principles of electrostatics (forces, fields, and electric potentials) in dc circuits.

\section{Lesson 1: Introduction}

Goal: To stimulate students' motivation and curiosity.

Strategy: Presenting "funny" intriguing questions and discussing them in small groups. For example:

\section{Move! Move! Move!}

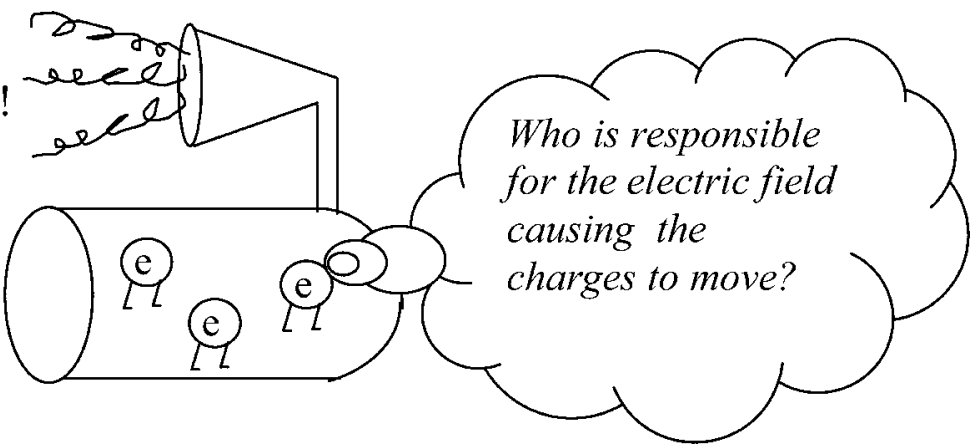

Lesson 2: The electric field in a current-carrying conductor.

Goal: To demonstrate the electric field in the vicinity of a current-carrying conductor.

Strategies: Shlomo Rosenfeld's ${ }^{a}$ experiment; Zvi Geller's ${ }^{a}$ movie.

Lesson 3: Charge distribution and its effect on the electric field.

Goals: To understand the relationship between concepts in electrostatics and phenomena in current-carrying conductors; To understand the microscopic processes in a conductor when the circuit is closed.

Strategies: Work sheets for analyzing various situations-open circuits, closed circuits with one conductor, closed circuits with a resistor (according to Sherwood's book); theoretical summary of charge distribution (by the teacher).

Lesson 4: Summary

Strategy: Summarizing exercise.

${ }^{\mathrm{a}}$ Expert physics teachers.

implementation of the minimodules, developed in the workshop, was natural for the teachers and did not require any logistical arrangements. Moreover, teachers were eager to identify "significant" differences between students who were exposed to this approach, and the "other" students.

85 students from three different schools were exposed to various aspects of the minimodule, immediately after they had finished the topics of charging and discharging of capacitors and before they had started learning about magnetism. The diagnostic questionnaire, described in step 3, served as the pretest for these students,
As a result of teaching the minimodule, the teachers assumed that their students would easily form the missing link between electrostatics and currents, in terms of electric fields and potentials. They proposed a posttest examining this assumption. The posttest was administered to the 85 students who studied the lessons ("experimental group") and to the matched classes of 68 students from the same schools ("comparison group"). The posttest and a qualitative analysis of the data were presented in Conference III (see Tables V and VI).

Because of the heavy teaching load and time constraints, teachers did not analyze students' responses to this posttest 
TABLE V. The posttest designed by the teachers.

\begin{tabular}{l}
\hline Posttest. \\
\hline 1. Draw a circle around the correct answer: Is there a relationship between electrostatics and dc circuits? \\
Yes (go to questions 2,3) \\
No (go to questions 4,5) \\
2. If you claim that there is a relationship between these two topics, name one concept that relates these \\
topics. \\
3. Briefly explain the relationship. \\
4. If you claim that there is no relationship between these two topics, name one concept that belongs to \\
electrostatics and not to dc circuits and one concept that belongs to dc circuits and not to electrostatics. \\
5. Explain briefly why there is no relationship between these two topics.
\end{tabular}

quantitatively. The group carried out a qualitative analysis in the following manner: First, each teacher read through all the posttests of his/her class, and summarized the major findings supported with selected examples. Then, the group convened to compare and contrast the findings and reached consensus on several conclusions. The teachers further supported the conclusions via discussions in their classes. Finally, the group was able to report on the superiority of the experimental group over the comparison group in some aspects but not in some other crucial aspects.

The teachers claimed that the ultimate goal of the minimodule, i.e., relating electrostatics to currents, was not fully accomplished. More specifically, the experimental group outperformed the control group only in aspects (a), (b), and (c) (see Table VI). Presumably, they expected their students to gain the same level of understanding as they themselves had gained in this program.

As one of the teachers said: "I'm kind of disappointed; I really hoped that it will work out better for the students."

Another teacher said: "We should examine more carefully what really happened in these classes. Maybe we should interview a few students to find out if there was progress in their understanding".

They decided to rewrite certain parts of the minimodule and to reemphasize the relationship between field, potential, and currents. These steps concluded the development of the minimodule

Step 10: Paper summarizing the process. Each group writes a paper summarizing the process and submits it to "TEHUDA" the journal of Israeli physics teachers.

Results. The "From electrostatics to currents" group wrote a paper published in TEHUDA bringing together their products described in the previous steps. The teachers described the rationale promoting the development of the minimodule, the diagnostic tool, and the analysis of students' answers, the detailed structure of the module, the posttest, and its analysis. They concluded the paper with further information regarding the difficulties they encountered with the implementation of the minimodule and how they plan to improve the materials. In the conclusions of the paper they describe their own benefit from the whole process (including writing the paper), mainly through an increased sensitivity to students' difficulties and their desire to find new ways to deal with these difficulties.

\section{B. The other groups}

The case study that we have described thus far illustrates how the workshop indeed provided opportunities for the teachers to achieve the different goals that the model set forth to support. Very similar results were found for the other three groups as well. In this paper we cannot describe them in detail; the following are a few examples.

The "Electromagnetic induction" group went through the same process. At the beginning of the workshop they questioned the benefit of developing a minimodule for such a

TABLE VI. Teachers' analysis of data collected from 85 "experimental group" students and 68 "comparison group" students.

Presentation of results by the teachers

(a) The experimental students regarded the concepts of potential and electric fields as meaningful concepts relating electrostatics and currents.

(b) The experimental students regarded charges in electrostatics as identical to charges in dc circuits.

(c) The experimental students preferred the relationship between current and electric field rather than the relationship between current and potential difference.

(d) Frequent use of the relationship between the electric field and potential was not found in the experimental group.

(e) The experimental students did not really grasp the idea that the static and dynamic phenomena in a dc circuit share a common feedback mechanism. 
"banal" topic. For example, one of the teachers said: "There is nothing surprising about it, teachers know exactly how to do it." Therefore, the initial plan of their minimodule included all the concepts and laws listed in the syllabus, such as flux, induced EMF, and Faraday's law and it was supposed to be taught in 14 lessons.

As a result of the group's analysis of the diagnostic questionnaire, the teachers modified their initial plans and narrowed the scope of the minimodule. Instead of the whole topic of electromagnetic induction, they decided to focus on the introduction to electromagnetic induction. In particular, a. designing demonstrations presenting the various mechanisms producing an EMF and especially the induced EMF, and b. composing qualitative questions discussing the role of the magnetic field in transforming work to electric energy during the motion of a loop in a magnetic field.

Another example from the "Introduction to waves" group illustrates the importance of working within a community of practice. This group designed a clumsy didactic means for demonstrating the concept of "waves." With the help of their colleagues they improved the model and turned it into a useful and inexpensive device.

\section{Teachers' views about the contribution of the workshop}

Immediately after completing the program, the teachers were asked to single out a framework or activity that was most meaningful, useful, and/or important to them.

About $80 \%$ of the teachers singled out the development of the minimodules.

Six years after the completion of the course, we located 15 teachers who had participated in the course and administered to them a questionnaire examining: a. the contribution of the minimodule workshop to the desired goals and $b$. the possible contributions of the minimodule workshop to the development of teachers' awareness of the importance of PER and to the actual use of the PER results in their present practice. The results indicate that even six years after the completion of the workshop, the teachers reported on the importance of all the goals, and about the significant contribution of the workshop to their attainment. Most of the teachers also claimed that they continue to use in their practice, PER-based materials or insights originating from PER.

\section{Summary of results}

In summary, the results reported in this section indicate the contribution of the workshop to the attainment of the goals mentioned above. Table VII summarizes the evidence supporting the conclusions for each of the goals. As can be seen, each step of the model contributed to the attainment of several goals. Another indication for the contribution of the model comes from the regional workshops, led by the teachers after completing our program. We monitored these regional workshops for several years and administered different questionnaires. In addition, Shayshon ${ }^{40}$ conducted a case study for four years in one of the regional programs. One of the most popular activities turned out to be the development of a minimodule. For example, in a regional workshop, ob- served by her, teachers developed such minimodules in optics, mechanics, and electrostatics. While the first implementations of the model in the regional workshops followed rigorously the model described above, later implementations involved customizations to local needs.

As to the effects on actual practice, in the context of the study there was a clear effect as indicated by the materials brought to the workshop by the teachers. The teachers also reported that they continued to use the insights gained mainly in the topics that were investigated by themselves and by their peers. However, additional research is needed to verify these reports.

\section{DISCUSSION}

The detailed description of the case study as well as the immediate and long-term results about teachers' views indicate that the desired goals concerning physics education research were accomplished. The results also suggest that in addition to the goals concerning PER, other important goals have been promoted. Teachers realized that even in the standard topics of high-school physics there is more to learn both about content and about pedagogical content knowledge-an important outcome for the experienced audience that we worked with. Furthermore, the fact that what we teach is not necessarily what students learn, ${ }^{41}$ and the need to better match the two was a main insight by the teachers, which was repeatedly mentioned in the different steps of the workshop. It should be noted that one cannot expect teachers to become expert curriculum developers who routinely use a researchbased approach and follow rigorously the process that was modeled in the workshop. Indeed this was not a goal we were aiming at. Rather, we anticipated that the fact that teachers had an opportunity to go through this experience would provide them with anchors to future work. We expected that teachers who go through such a process would become better consumers of innovative materials and approaches since they acquired tools to customize them to their practice. This claim needs further investigation.

The long-term intensive nature of teachers' activities in this program enabled the teachers to develop professionally. However, this same characteristic of the program led to several implementation difficulties because of the large investment required from the teachers. Since we worked with these teachers previously and won their trust, they were willing to give us the credit and join the journey. With experience, teachers realized the importance of the long process. This same strategy may not be successful in occasions in which teachers do not give such credit to the professional development program providers. Hence one has to reconsider how to carry out the model in such occasions, while preserving its central characteristics. For example, one can use formats focusing more on the diagnostic stages and less on development, or alternatively, formats for introducing innovative curricula into schools by using existing materials and revising them instead of designing lessons from first principles. ${ }^{42}$ What is common to all these versions is the systematic and research-based approach to instructional design.

A central insight emerging from this research and being used in our present instruction in teachers' programs is con- 
TABLE VII. Summary of claims and evidence for impact of the workshop.

\section{Claims}

\section{Goal 1:}

Teachers developed awareness of deficiencies in their knowledge of physics, of pedagogy, and of their students' knowledge.

They experienced difficulties as learners.

They were willing to extend their knowledge.

\section{Goal 2:}

Teachers advanced their content knowledge, pedagogical content knowledge, and pedagogical knowledge.
Evidence supporting the claims

(1) Teachers indicated surprise at the difficulties that they encountered as learners (e.g., in constructing concept maps of central ideas).

(2) They requested to meet experts to help with issues raised in constructing the maps.

(3) They described new revelations concerning the physics topic and its learning.

(4) They reported mismatch between their expectations and their students' poor performance in the posttest.

\section{Artifacts:}

(1) The final concept maps represented the missing link between electrostatics and current which was absent from the initial maps.

(2) Teachers' redefinition of goals and the diagnostic questionnaire related to the missing link and was closely aligned with the final maps.

(3) Teachers' review of the literature emphasized important pieces of knowledge regarding the physics and learning of the topic.

(4) The lessons reflected the new knowledge by using research-based instructional strategies and applying a student-centered approach.

Discourse and reports:

(5) Teachers expressed satisfaction regarding the opportunity to learn more physics and the teaching of physics.

(6) They reported on the benefit in the TEHUDA paper, and in feedback questionnaires.

(7) They were able to explain students' mistakes in terms of deficiencies in understanding.

(8) They discussed the implications of aspects such as diagnosis to their teaching in general.

\section{Goal 3:}

Teachers carried out a goal driven, diagnosis-based iterative design process supported by the resources that were supplied by the workshop.

\section{Coherence between the various aspects of design:}

diagnostic questionnaire with the literature review; redefinition of goals with review of the literature and the diagnosis; the structure of the minimodule reflected the review of the literature as well as the diagnosis and the contribution of expert teachers; the posttest examined the intended goals.

Teachers reports: in interviews and questionnaires about the importance of the systematic-research based design approach and on the contribution of the workshop to this aspect.

\section{Goal 4:}

Development of a community of practice.

This aspect of the workshop was highly appreciated by the teachers
This claim is supported mainly by our observations, informal talks with the leaders of the course, and acquaintance with some of the teachers.

\section{Teamwork developed as time went on:}

(1) From formats dictated by the course to initiatives by the teachers.

(2) From concerns to expose to other participants deficiencies in one's knowledge, towards friendships and readiness to share frustrations and even ask for help.

(3) Teachers shared responsibility in the various assignments.

(4) Teachers continued to collaborate after the completion of the workshop.

Teachers reported in interviews and questionnaires on the importance of a community of practice and the model's contribution to its attainment.

\section{Overarching goal:}

Learning about PER findings and their relevance to their practice. The attainment was interwoven with the other goals.
Each step contributed to somewhat different aspect of the PER goal as shown by the following examples:

(1) Learning about students' conceptual difficulties, and tools how to assess understanding (step 3);

(2) Innovative PER-based teaching strategies (step 5);

(3) Implementation of the lessons and its evaluation made extensive use of the PER results (step 8). 
cerned with cognitive conflicts activated by examining students' work. Teachers in the workshop described in this paper experienced cognitive conflict processes several times. In the diagnosis step teachers realized that there is a gap between what "I've taught" and what students actually learned motivating them to "fix" their previous teaching by trying out new instructional strategies. Towards the end of the workshop they encountered an additional cognitive conflict as a result examining again their students' answers to the posttest. They found a gap between what they tried to achieve and the actual disappointing outcomes. This cognitive conflict could have served as a starting point for a follow-up workshop with the same teachers aimed at changing their perceptions about the relationship between teaching and learning. ${ }^{41}$ This follow-up support of teachers was not carried out and was a weakness of the approach.
The insights gained from this workshop, about the power of a cognitive conflict intertwined with examining, reflecting, and discussing one's practice (referred to as an "evidencebased approach"43), paved the way to new professional development programs. We found repeatedly that the careful iterative examination of students' work demonstrates dynamically the stepwise gradual nature of changes in students' learning and enables the teachers to customize their teaching accordingly.

\section{ACKNOWLEDGMENTS}

We wish to thank the leading teachers participating in our program. Special thanks to Hana Berger, Henia Wilf, Shmuel Meirman, David Moravia, Dganit Soroker, and the late Refael Shapira, the "From electrostatics to currents" group.
${ }^{1}$ L. C. McDermott and E. F. Redish, Am. J. Phys. 67, 755-767 (1999), see also, Bibliography - STCSE, Students' and Teachers' Conceptions and Science Education, Compiled by Reinders Duit (2006).

${ }^{2}$ R. Hake, Am. J. Phys. 66, 64 (1998).

${ }^{3}$ D. C. Smith and D. C. Neale, in Advances in Research on Teaching: Vol. 2: Teachers' Knowledge of Subject Matter as it Relates to their Teaching Practice, edited by J. Brophy (JAI Press, Greenwich, CT, 1991), pp. 187-243.

${ }^{4}$ L. S. Shulman, Educ. Res. 15, 2 (1986).

${ }^{5}$ B. Eylon and E. Bagno, in The Changing Role of Physics Departments in Modern Universities, Proceedings of ICUPE, edited by E. W. Redish and J. S. Ridgen (American Institute of Physics, Melville, NY, 1997), pp. 299-326.

${ }^{6}$ R. Putnam and H. Borko, Educ. Res. 29, 1 (2000).

${ }^{7}$ G. J. Whitehurst (unpublished).

${ }^{8}$ C. Fernandez and M. Yoshida, Lesson Study: A Japanese Approach to Improving Mathematics Teaching and Learning (Lawrence Erlbaum, New Jersey, 2004).

${ }^{9} \mathrm{~K}$. Roth (unpublished).

${ }^{10}$ P. Black, Ch. Harrison, B. Marshall, C. Lee, and D. William, Assessment for Learning - Putting it into Practice (Open University Press, Berkshire, 2004).

${ }^{11}$ A. L. Brown, J. Learn. Sci. 2, 2 (1992).

${ }^{12}$ S. Rosenfeld, N. Orion, B. Eylon, and Z. Scherz (unpublished).

${ }^{13}$ S. Loucks-Horsley, P. W. Hewson, N. Love, and K. E. Stiles, Designing Professional Development for Teachers of Science and Mathematics (Corwin Press, Inc., Thousand Oaks, 1998).

${ }^{14}$ R. Pinto, Sci. Educ. 89, 1 (2004).

${ }^{15}$ National Commission on Teaching and America's Future, What Matters Most: Teaching for America's Future (New York, NY, 1996).

${ }^{16}$ L. Darling-Hammond, Educ. Res. 27, 10 (1998).

${ }^{17}$ H. Borko, Educ. Res. 33, 8 (2004).

${ }^{18} \mathrm{C}$. W. Anderson, in Research Perspectives on the Graduate Preparation of Teachers, edited by A. Woolfolk (Prentice-Hall, Englewood Cliffs, NJ, 1989).

${ }^{19}$ D. L. Ball, Elem. Sch. J. 90, 449 (1990).

${ }^{20} \mathrm{H}$. Borko and R. Putnam, in Handbook of Educational Psychol- ogy, edited by D. Berliner and R. Calfee (MacMillan, New York, 1996), 673-708.

${ }^{21}$ D. McDiarmid, L. Ball, and C. Anderson, in Knowledge Base for the Beginning Teacher edited by M. C. Reynolds (Pergamon, New York, 1989), 193-205.

${ }^{22} \mathrm{R}$. Hollon, K. Roth, and C. Anderson, in Advances in Research on Teaching, edited by J. Brophy (JAI Press, Greenwich, CT., 1991), Vol. 2, pp. 145-186.

${ }^{23}$ L. S. Shulman, Harv. Educ. Rev. 57, 1 (1987).

${ }^{24}$ Examining Pedagogical Content Knowledge, edited by GessNewsome and N. Lederman (Kluwer, Boston, 1999).

${ }^{25}$ Sh. Magnusson, J. Krajcik, and H. Borko, in Examining Pedagogical Content Knowledge, edited by Gess-Newsome and N. Lederman (Kluwer, Boston, 1999), 95-132.

${ }^{26}$ D. L. Ball, S. T. Lubiensky, and D. S. Mewborn, Handbook of Research on Teaching, 4th ed. (Macmillan, New York, 2001), pp. 433-456.

${ }^{27}$ J. Stigler and J. Hiebert, The Teaching Gap: Best Ideas from the World's Teachers for Improving Education in the classroom (Free Press, New York, 1999).

${ }^{28}$ S. M. Chokshi, NAS/National Research Council Board on International and Comparative Studies in Education, 2002 (unpublished).

${ }^{29}$ J. W. Little, Teach. Teach. Educ. 18, 917 (2002).

${ }^{30}$ P. Grossman, S. Wineburg, and S. Woolworth, Teach. Coll. Rec. 103, 942 (2001).

${ }^{31}$ V. K. Otero (unpublished).

${ }^{32}$ D. Hestenes, in The Changing Role of The Physics Department in Modern Universities, edited by E. Redish and J. Rigden (American Institute of Physics, New York, 1997), Pt. II, pp. 935-957.

${ }^{33}$ P. S. Shaffer and L. C. McDermott, Am. J. Phys. 73, 921 (2005).

${ }^{34}$ How People Learn: Brain, Mind, Experience and School, edited by J. Brownsford, A. Brown, and R. Cocking (National Academy Press, Washington, DC, 1999).

${ }^{35}$ M. C. Whittmann, R. N. Steinberg, and E. F. Redish, Phys. Teach. 37, 15 (1999).

${ }^{36}$ B. Eylon and U. Ganiel, Int. J. Sci. Educ. 12, 1 (1990).

${ }^{37}$ E. Bagno and B. Eylon, Am. J. Phys. 65, 726 (1997).

${ }^{38}$ R. Chabay and B. Sherwood, Electric and Magnetic Interactions 
(John Wiley \& Sons, New York, 1995); O. Jefimenko, Am. J. Phys. 30, 19 (1962); O. Jefimenko, Phys. Teach. 15, 52 (1977); W. R. Moreau, European Journal of Science Teaching 10, 286 (1989); R. Cohen, B. Eylon, and U. Ganiel, Am. J. Phys. 51, 407 (1983).

${ }^{39}$ L. C. McDermott and the Physics Education Group at the University of Washington, Physics by Inquiry (John Wiley \& Sons, New York, 1996); A. Van-Heuvelen, Overview Case Study Physics (Hayden-McNeil Publishing, Plymouth, MI, 1996); F. Reif and S. Allen, Cogn. Instruct. 9, 1 (1992); R. Chabay and B. Sherwood, Electric and Magnetic Interactions (John Wiley \& Sons, New York, 1995).

${ }^{40}$ B. Shayshon, Doctoral thesis, The Weizmann Institute of Science, 2001.

${ }^{41}$ L. C. McDermott, Am. J. Phys. 59, 301 (1991).

${ }^{42}$ B. Eylon and E. Bagno (unpublished).

${ }^{43}$ R. Putnam and H. Borko, Educ. Res. 29, 4 (2000). 